Genij Ortopedii. 2021. Vol. 27, no. 5. P. 658-668.

Review article

https://doi.org/10.18019/1028-4427-2021-27-5-658-668

\title{
Extension-abduction contracture of the hip joint as a consequence of gluteal fibrosis
}

\author{
Ertine S. Chyndyn-ool ${ }^{1 \bowtie}$, Vitaliy V. Pavlov ${ }^{2}$, Aleksandr G. Samokhin ${ }^{3}$
}

\author{
1,2,3 Novosibirsk Research Institute of Traumatology and Orthopaedics N.a. Ya.1. Tsivyan, Novosibirsk, Russian Federation \\ 1MynameisTreasure@mail.ru \\ 2pavlovdoc@mail.ru \\ 3motorist@inbox.ru
}

\begin{abstract}
Introduction The disease that is manifested by primarily induced fibrotic changes in the gluteal muscles resulting in hip contractures and, in particular, in extension-abduction contracture of the hip joints has been known in the English literature as the "gluteal muscle contracture" and "gluteal fibrosis". The world literature on the subject covers this pathology mostly in pediatric and adolescent patients, whereas this disease has not been sufficiently discussed in the adult patients, even in foreign studies. Therefore, diagnostic methods, methods of examination and treatment of adult patients have not been systematized and this nosology presents certain clinical and diagnostic difficulties for many domestic orthopedists. Materials and methods We searched the PubMed and eLibrary systems for studies on the topic and used combinations of key words "gluteus muscle contracture", "gluteal fibrosis", "gluteus maximus contracture", "abduction contracture of the hip", "extension-abduction contracture of the hip", "aplasia of gluteal muscles" published from October 1974 to February 2020 and found a total of 106 results. The first publication coincides with the date of the initial search period. The criteria for including studies in the analysis were a discussion of the issues of etiology and pathogenesis, epidemiology, diagnostic criteria, clinical presentation, and approaches to the treatment of this pathology. We excluded articles related to the installation of gluteal implants and other pathology of the gluteal region, so the number of articles decreased to 67, what means little investigation of this problem. Results Our analysis showed that out of 67 articles, only 9 articles were related to issues of etiology and pathogenesis, five articles dealt with epidemiology, 15 dealt with diagnostic criteria, treatment options were described in 12 articles, and the majority of publications focused on the results of surgical treatment of clinical samples including 1-2 to 1280 cases. In the context of the 50-year-old depth of the literature search, the analysis indicates the fragmentation of the material devoted to the gluteal muscle fibrosis published over this period of time, which requires the systematization and generalization of the literature data accumulated to date. Conclusion Gluteal fibrosis is a rare independent disease, which is prevalent among certain ethnic groups. The extension-abduction contracture of the hip joint develops due to gluteal fibrosis, the clinical picture of which has been very well documented and has specific radiological signs. Surgical treatment methods vary, from open to endoscopic treatments and minimally invasive techniques. Since the main group of patients described in the literature is children and adolescents and the surgical methods used are discussed for these age groups, treatment methods and their efficacy for adult patients have been little reported. Therefore solution making is difficult for patients older than 18 years. It primarily refers to providing specialized orthopedic care in places where ethnic groups with this pathology reside.
\end{abstract}

Keywords: Gluteal fibrosis, extension-abduction contracture of the hip joints

For citation: Chyndyn-ool E.S., Pavlov V.V., Samokhin A.G. Extension-abduction contracture of the hip joint as a consequence of gluteal fibrosis (literature review) Genij Ortopedii, 2021, vol. 27, no 5, pp. 658-668. https://doi.org/10.18019/1028-4427-2021-27-5-658-668

\section{INTRODUCTION}

Extension and abduction contracture of the hip joint $(\mathrm{EACHJ})$ is a pathological condition caused by a violation of the elasticity of the muscles responsible for extension, abduction and external rotation of the hip due to developed idiopathic fibrotic changes. In the world literature, this pathology is referred to as "gluteal muscle contracture" (GMC) or "gluteal fibrosis" (GF), fibrosis of the gluteal muscles, and was first described by Fernandez de Valderrama in 1970 [1]. The gluteal muscles, the iliotibial tract and associated fascia, the muscles that rotate the femur outwards, and, in severe cases, the capsule of the hip joint, undergo a fibrotic process [2-5]. Contracture of the hip joint develops due to the fibrotic process in the muscles and is manifested by the limitation of movements in the hip joint and in some cases leads to anatomical deformity such as asymmetry in the length of the lower extremities [6-8]. Patients have enormous difficulties in daily and social activities, including by physiological bowel and bladder functions, which significantly lowers their social status in society [2-4, 8-11].

The purpose of this literature review is to study the problem of diagnosis and treatment of such a rare pathology as extensor-abduction contracture due to fibrosis of the gluteal muscles, which is characteristic of small ethnic groups and presents difficulties in diagnosis and treatment for orthopedic specialists.

\section{MATERIAL AND METHODS}

For investigation of RACHJ in adult patients, we analyzed the available literature. PubMed and eLibrary systems were searched with combinations of key words "gluteus muscle contracture", "gluteal fibrosis", "gluteus maximus contracture", "abduction contracture of the hip" from October 1974 to February 2020. We found only 106 results, and the first publication coincides with the date of the initial search ppoint. Search for publications applied the keywords in the title, introduction and throughout the text of the 
publication without specifying territorial affiliation, gender and age criteria. The criteria for inclusion of the studies in the analysis were the discussion of the issues of etiopathogenesis, epidemiology, diagnostic criteria, clinical presentation and approaches to the treatment of this pathology. Studies related to the installation of gluteal implants and other pathology of the gluteal region were excluded. The total of selected studies was only 68 publications, what means little investigation of this problem.

\section{RESULTS}

Analysis of these publications shows the degree of coverage according to the inclusion criteria. Thus, of the total, only 9 articles deal with issues of etiopathogenesis, 5 articles are devoted to epidemiology, 16 to diagnostic criteria, treatment approaches are described in 13 articles, and the overwhelming number of publications are focused on the results of surgical treatment of the samples of clinical cases, which in the context of the 50-year depth of the search, indicates the fragmentation of the material on gluteal fibrosis published over this period of time.

Certain doubts about the quality of the search are caused by a small number of articles on the above problem in the world literature, but it coincides with the search results conducted by other authors. Thus, Kristin Alves et al. analyzed the literature related to the diagnosis, pathogenesis and prevalence of fibrosis of the gluteal muscles, as well as the results of treatment of this pathology. The literature search conducted by the authors found only 82 articles devoted to the GF from 2,512 sources. Among 82 sources, 18 articles dealt with surgical outcomes. The surgical procedures described in those works may be divided into three methods, open, minimally invasive and endoscopic muscle release from the scars. Six provided treatment outcomes in 3,733 patients who underwent surgical treatment. In $83 \%$ of cases, they were rated as good [12]. Saroj Rai et al. also showed treatment outcomes with a variety of modalities in their literature review. Thus, the authors point out that the non-operative method of physiotherapy did not lead to positive results as an independent method. Surgical methods (open, minimally invasive and endoscopic ones) resulted in positive clinical outcomes [13]. By comparing surgical methods of treatment, various authors noted that the advantage is in favor of the endoscopic method only in terms of cosmetic results [13-15]. Moreover, most publications deal with the problem of this pathology in children and adolescents. There are only 13 publications related to the treatment of RACHJ in adults published worldwide [8, 15-26].

Clinical picture

The pathological complex of RACHJ symptoms is manifested in patients by hip joint dysfunction. Patients are unable bend the hip in the sagittal plane. The hip rotates outwards in flexion and abducts to the side. In bilateral involvement, squatting (flexion in the hip and knee joints) is possible only in the so-called "frog pose". Thus, deep squats and anterior bending of the body with the knees brought together become impossible. Therefore, what is commonplace for healthy people (sitting at the table correctly, relieving daily physiological functions, nuances of sexual life in adults) becomes difficult for patients with this pathology. They also have a pathological "waddling" gait stereotype, secondary cosmetic disfiguring defects in the buttock region due to underdevelopment or metaplasia of the gluteal muscles (Fig. 1) [2-5, 8, 9, 16, 19-21, 24-37]. Some authors point to additional diagnostic criteria, such as crepitus and pain along the anterior surface of the knee joint resulting from the patellofemoral conflict, a positive Ober's test $[6-8,11,14,18,20,22,23$, $38-45]$ and reverse Ober's test [12, 33], compensatory lumbar scoliosis and apparent lengthening of the lower limb on the affected side due to pelvic misalignment caused by constant tension of fibrotic alterations in the gluteal muscles [8, 12-14, 23]. Thus, Xintao Zhang et al. reported a discrepancy in the length of the lower extremities in 118 patients out of 140 [8].

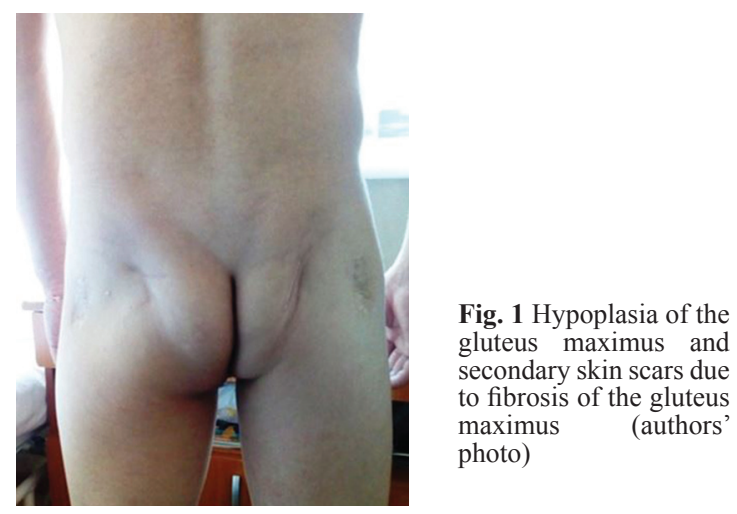

A positive Ober's test, which indicates a contraction of the iliotibial tract [33], and according to some data, also a contracture of the gluteus medius and minimus muscles [11], is characterized by an increased abduction in extension of the flexed and adducted femur (Fig. 2) [11, 33].

A positive reverse Ober's test indicates a contracture of the gluteus maximus muscle and is manifested by an increase in the hip abduction that occurs when the extended and adducted femur flexes in the hip joint to 90 degrees or more (Fig. 3) [33].

\section{Epidemiology}

$\mathrm{RACHJ}$ is a rare pathology in adults. It is confirmed by only 13 publications in the world literature $[8,14$, $16-26,45]$. This pathology is often found in China $[8,14,16,17,19-26,45]$ and, in descending order, in Brazil [18], India [38] and Russia [22]. On the territory of the Russian Federation, the disease occurs in persons of Tyva nationality, which is due to the complex geographical landscape of the Republic of Tyva contributing to closely related marriages [9]. 


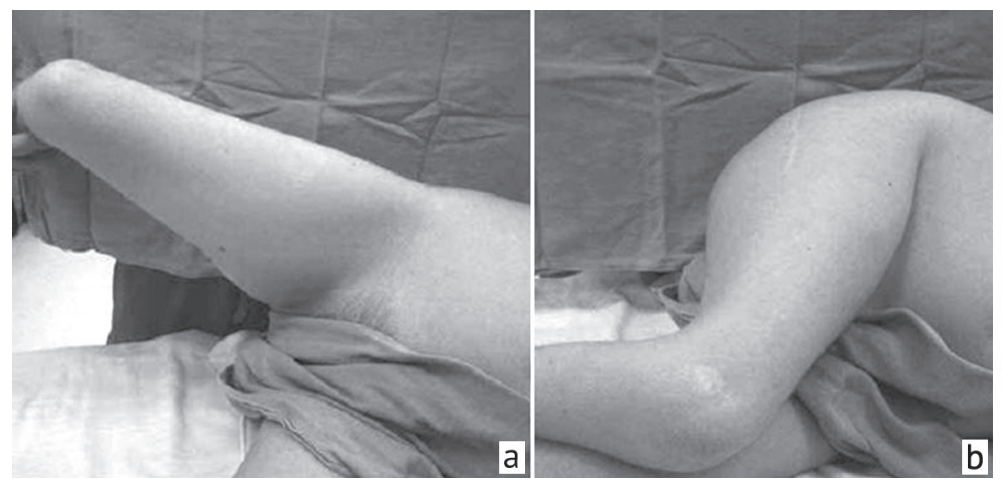

Fig. 2 Ober's test indicates fibrosis of the iliotibial tract [33], also fibrosis of the gluteus medius and minimus muscles according to some data [11]: a increase in femur abduction by extension in the hip joint with the knee joint bent to 90 degrees; b starting position by performing the Ober's test, where flexion in the hip and knee joints is 90 degrees [33]

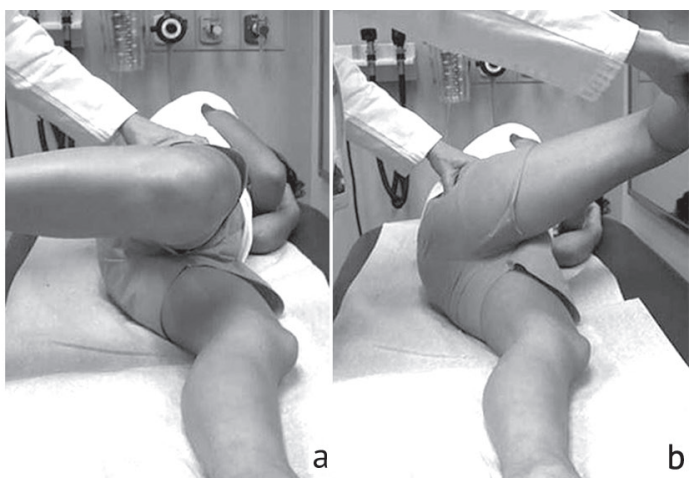

Fig. 3 Ober's reverse test indicates fibrosis of the gluteus maximus: a initial position, where the researcher holds the lower leg with one hand, bends the knee to 90 degrees, and fixes the patient's pelvis with the other hand; $\mathrm{b}$ in hip flexion up to 90 degrees together with the bent knee joint, the femur is abducted due to the fixed passage of the fibrously altered gluteus maximus over the greater trochanter, what indicates fibrosis of the gluteus maximus [33]
In turn, this pathology is not considered rare in children and has been well described by many authors from different countries. The largest number of publications are from Eastern [3, 4, 6, 7, 11, 14, 29, 32, 34, 43, 46-49, 51-53], Central [9, 44], Southern [10, $28,39,41,54,55]$ and Western Asia [50, 56], fewer from Africa $[35,36]$ and rare publications refer to North America [33, 42, 57] and Europe [1, 2, 5, 22, 30$]$. Basically, this pathology occurs in preschool children, mainly in boys and is more often bilateral $[6,7,9$, $11,13,16,17,20,24,28,29,32,47,49]$. According to Chung et al., the incidence of this pathology in children from 6 to 19 years old was 17.3 cases per 1,000 in boys, and 10.5 cases per 1,000 in girls in the study region Jia-Dong Township, a rural town in Pingtung County, Taiwan [29]. Sun showed that in the region of Mianyang (Sichuan, China) the incidence of pathology in 9,845 children from 3 to 12 years old was $1.36 \%$ [34]. Only one study has been conducted in Russia, and the author A.V. Dongak showed that the incidence of this pathology in the region of the Tyva Republic was 2.2 cases per 1,000 children [9].

Rare publications in North America are explained by a still small number of detected cases by "unplanned medical pathology" in adopted children of a different race from orphanages in developing countries. Scully et al. indicates that the pathology is rare in the United States, but has a sufficient prevalence in Russia and China [33].

Etiology and pathogenesis

There is no consensus on the etiology of RACHJ in the world literature. Four hypotheses of etiology have been proposed: idiopathic $[6,10,11,22,38,39$, 56], congenital [27, 40,41, 50, 54, 56-59], genetic/ hereditary $[4,9,11,27,42,60]$ and acquired $[2-7$, $11,14-21,23-26,28-36,43,46-49,51,61,62]$.

An etiological relationship has been established between intramuscular injections of antibiotics and antimalarial drugs in the gluteal region and the subsequent development of RACHJ. In the English- language literature, the developed thus changes are called "injection-induced" contractures of the gluteal muscles [33]. A simple mentioning of the treatment of malaria or other infection with the use of intramuscular injections in the medical case history allowed the authors with a high degree of confidence to associate the development of fibrosis with injections. However, our own search in the PubMed system for the combination "injection induced gluteal muscle contracture" yielded only 13 results, starting from 1987 to 2020, which reflects a lack of interest in this problem or its low incidence.

This can be demonstrated by the article of J. Ekure "Gluteal Fibrosis" (2006) in which the author described the treatment of 28 adolescents with injection-induced fibrosis of the gluteal muscles for the period from August 2004 to May 2006. In all cases, the treatment was surgical, and with complications. In two cases, the postoperative period was complicated by sepsis, and in one case the patient developed paresis of the peroneal portion of the sciatic nerve, possibly associated with myolysis of the thigh muscles. But the author's conclusion is interesting: "None of our cases of gluteal fibrosis was diagnosed at birth, and therefore all of the cases reported here were secondary to mostly Quinine injections. Gluteal fibrosis is a preventable condition if proper administration of Quinine, mostly by IV route is emphasized" [35]. In the list of references, the author refers to sources published in 1969, 1970 and 1973, which coincides with the geopolitical processes on the African continent when European volunteer doctors, providing medical care to the local population, encountered clinical pathologies characteristic of ethnic groups of the peoples of Africa. It would seem that there was a reason to study the pathology, but the scientific community probably had little interest in studying the pathologies of ethnic groups at the time of the publication by the author in 2006 .

Thus, Rai et al. [13] and Liu et al. [20] explained the development of fibrosis in muscle tissues by the 
fact that drug diluents and repeated intramuscular administration of a large volume of fluid are damaging, causing inflammatory reactions in muscles and their further replacement by connective tissue. According to morphological studies, fibrosis of perimysium and endomysium with nonspecific degeneration, regenerative changes and, in some cases, with signs of denervation occurs in the muscle structure [44, 54, 63]. In 1988 Gao [4] suggested that the pathology does not occur in all children who received repeated intramuscular injections of antibiotics in the buttocks, but only in those children who had a certain predisposition to this pathology. This theory was supported by research by Liu et al. [20], Chung et al. [29], Sun [34], Ekure [35] and Nikolaou et al. [36], who found that only children who received repeated intramuscular injections of antibiotics or antimalarial drugs in the gluteal region had RACHJ. But why in children of Europe and North America, where there was a widespread use of intramuscular injections, fibrosis of the gluteal muscles with the development of contractures of the hip joint was not observed, and this pathology was detected in other ethnic groups?

As for other hypotheses - idiopathic, congenital, genetic, there is no reliable information in the literature about the etiology, epidemiology, genetic diagnosis and prevention of RACHJ, only a few publications describing clinical cases. The authors whose publications present patients with this pathology who do not have a history of repeated intramuscular injections into the buttocks, do not have any other diseases, were born healthy and whose parents were also healthy, characterized the etiology of their disease as idiopathic $[6,10,11,22,38,39,56]$. The lack of a relationship between the developed fibrosis of the gluteal muscles with intramuscular injections was described by Indian colleagues Aditya Aggarwall et al. on the example of a 14-year-old girl [10]. Colleagues from Iraq, M.A. Al Bayati and B.K. Kraidy, also describe fibrosis of the gluteal muscles with abduction contracture of the hip in 6 boys and one girl treated with open surgical approach with good results [56]. A. Ganel and A. Blankstein in 1989 described a single case of fibrosis of the gluteal muscles with contracture of the hip joint, identified in a three-year-old boy in Israel, which is a casuistic case for this country, and, like the above cases, is probably associated with abnormalities at the genome level [50].

The absence of intramuscular injections in the anamnesis of adolescents prompted researchers to search for other pathogenetic mechanisms of fibrosis. It is supposed that it occurs due to a violation of the processes of fibroblast proliferation with further quantitative changes in different types of collagen. Thus, Chen-Guang Zhao et al. studied the expression of genes for collagen type I, type III and transforming growth factor beta (TGF- $\beta$ ) in 23 fibrously altered patients' samples and in 23 normal control samples using immunohistochemical methods and methods of reverse transcription polymerase chain reaction (RT-PCR) ) and analysis of protein immunoblotting. Compared with normal adjacent muscle, an increased expression of TGF- $\beta 1$ and $-\beta 3$ in the fibrous muscle of patients was associated with the deposition of collagen types I and III. High increase in the expression of these proteins in the fibrotic muscle was confirmed by immunohistochemical staining and protein immunoblotting. TGF- $\beta 2$ was not elevated in fibrotic muscles. This study confirmed the authors' hypothesis that collagen types I, III, TGF-1 and TGF-3 were elevated in biopsy samples obtained from patients with idiopathic gluteal fibrosis. The complex interaction of TGF-1 with profibrotic function and TGF- $\beta 3$ with antifibrotic function can enhance collagen synthesis and thereby significantly contribute to the process of scarring of the gluteal muscle in patients with GMC. Histological and immunohistochemical studies have shown the role of TGF- $\beta$, a protein that controls proliferation and cell differentiation. Its mechanism of action is perhaps the most well understood, and it is a potent stimulant of fibrosis [64].

Moreover, Xintao Zhang et al. conducted a study on the role of TGF- $\beta$ in the pathogenesis and development of fibrosis of the gluteal muscles, leading to contracture of the hip joint. The authors regard this pathology as a chronic fibrotic disease of the gluteal muscles, which is characterized by excessive deposition of collagen in the extracellular matrix. They believe that transforming growth factor (TGF)-Bs plays an important role in the progression of gluteal muscle fibrosis. The authors investigated the expression levels of collagen type I/ III, TGF- $\beta 1$, Smad2/3/4/7 and PAI-1 (plasminogen activator inhibitor-1). They also, in support of the results of previous researchers, observed an increase in the expression of collagen type I/III and TGF- $\beta 1$ genes in the fibrosis zone compared to intact muscle. In addition, R-Smad phosphorylation and Smad4 protein expression in the fibrosis zone were also increased, while Smad7 expression was significantly reduced in the fibrous muscle of patients with gluteus fibrosis compared to intact adjacent muscle. PAI-1 protein and mRNA levels were also markedly increased in the area of fibrosis compared to adjacent muscles. Immunohistochemical analysis also showed that the expression levels of TGF- $\beta 1$ and PAI- 1 were higher in the zone of fibrosis than in the adjacent muscles [65].

The same results were obtained by Bangtuo Yuan et al. They conducted a comparative histological study of the samples of fibro-altered iliotibial tracts and areas of fibrosis of the gluteal muscles from 6 patients with samples of normal tissues of the same muscles that were taken from 6 patients during operations for avascular necrosis of the femoral head, without fibrosis of the gluteal muscles. The researchers stained tissue samples with hematoxylin and eosin, Masson's trichrome 
and Sirius red. The mRNA and protein levels of various tissue repair genes were determined using quantitative real-time polymerase chain reaction and protein immunoblotting. Both normal and fibroaltered iliotibial tracts consisted of type I and type III collagens. Tissue samples of fibro-altered iliotibial tracts had a significantly higher proportion of type III collagen compared to tissue samples of normal (unaltered) iliotibial tracts. The expression levels of mRNA and proteins of the genes for tissue repair TGF $\beta$ 1, bFGF and matrix metalloproteinase-1 (MMP-1) in tissue samples of fibro-altered iliotibial tracts were increased compared to those in normal iliotibial tracts. However, the level of expression of mRNA and proteins of tissue inhibitors of metalloproteinase-1 (TIMP) in the samples of fibroaltered iliotibial tracts was reduced compared to those in normal iliotibial tracts. Fibrous changes in both the gluteal muscles and the iliotibial tracts have similar histology and molecular pathology. The authors show that fibrosis of the iliotibial tract is secondary to fibrosis of the gluteal muscle and is a permanent process of tissue repair [63].

There are also publications without specifying closely related relationships, where children, along with RACHJ, were born with abnormalities, namely aplasia of the gluteal muscles, including aplasias of other muscle groups [27] and brain atrophy [58]. Aplasia of the gluteal muscles is a true pathology, and not a secondary fibrosis of the gluteal muscles. Carnevale et al. described congenital absence of gluteal muscles in combination with spina bifida occulta in two siblings. Moreover, both parents and two apparently normal siblings had spina bifida occulta. They proposed two alternative hypotheses of the etiology of the development of those defects: 1) the muscle defect may be caused by an autosomal recessive gene that does not predetermine the development of spina bifida occulta; 2) both types of malformations may be caused by the same autosomal recessive gene [57]. A similar report was made by Edgar et al. in 2012, indicating the congenital absence of gluteal muscles in combination with optic nerve hypoplasia and CNS hamartoma [40].

Other researchers found the connection of the disease in children with the same pathology in their parents $[9,11,27,42,60]$. The hereditary form is an autosomal recessive disease (MIM No. 231970 according to the McKusick catalog (1997)), which occurs in the individuals whose family tree has closely related marriages $[9,40,57]$. This fact is also confirmed by the publication of E. Parano et al. It reports three cases of familial unilateral hypoplasia of the buttocks. In addition to hypoplasia of the buttocks, all three also had unilateral hypoplasia of the pectoral muscle and one of them had unilateral symbrachydactyly of the distal phalanges of one foot. All relatives were female. The authors suggest that these cases are best classified as part of the "Polish complex of anomalies" and are a manifestation of intra-familial phenotypic heterogeneity [60]. We would like to note the fundamental difference between the nosology of congenital aplasia of the gluteal muscles combined with another congenital pathology from a nosology in which the development of true primary fibrosis is induced in initially normal gluteal muscles, leading to secondary RACHJ, which, in fact, is the subject of our clinical interest.

\section{Imaging methods}

Radiographic examination reveals an increase in the neck-shaft angle of the femur, a sign of external rotation of the femur, pelvic misalignment with the development of compensatory lumbar scoliosis and a "hyperdense iliac line" on the anteroposterior pelvic radiograph, which runs parallel to the sacroiliac joint $[4,6-10,13,16,20$, $22,33,34,37,38,44,47,54]$. This sign is formed as a result of a prolonged and persistent pulling effect of the fibrously altered gluteus maximus muscle, which deforms the lateral periosteum of the posterior part of the ilium from the oblique direction to the anteroposterior direction. So, the $\mathrm{X}$-ray beam passes parallel to the compacted lateral periosteum of the ilium, and a dense line is revealed on the radiographic image running parallel to the sacroiliac joint. Jin-Hua Cai et al. called it "a sign of a hyperdense line of the ilium" (Fig. 4), and suggested to use this term when describing this $\mathrm{X}$-ray sign in the process of preparing an X-ray report to diagnose fibrosis of the gluteal muscles.

Other imaging techniques have also been tested in affected patients. MRI studies revealed atrophy of the gluteus maximus muscle. Chen et al. conducted an MRI study to describe the MRI signs of fibrosis of the gluteal muscles after a retrospective analysis of the examination of 21 patients. It was concluded that fibrosis of the gluteal muscles is manifested by characteristic signs, such as 1) intramuscular fibrous bands extending to the thickened distal tendon with atrophy of the gluteus maximus muscle, 2) posterior medial displacement of the ilio-sacral tract, 3 ) in later stages (adults) the medial retraction of the gluteus maximus muscle and its tendon forms a depressed groove at the muscle-tendon junction by external rotation of the femur $[13,37,66]$. In the domestic literature, O.V. Kozhevnikov and S.E. Kralina described a case of MRI examination in a patient with RACHJ. They revealed hypotrophy of the gluteus maximus muscle and, additionally, hypotrophy of the quadratus femoris muscle on the affected side. They served as signs for the scope of surgical treatment performed by them, excision of not only the fibrously altered bands of the gluteus maximus muscle, but also the bands of the fibrously altered quadratus femoris muscle [22]. 

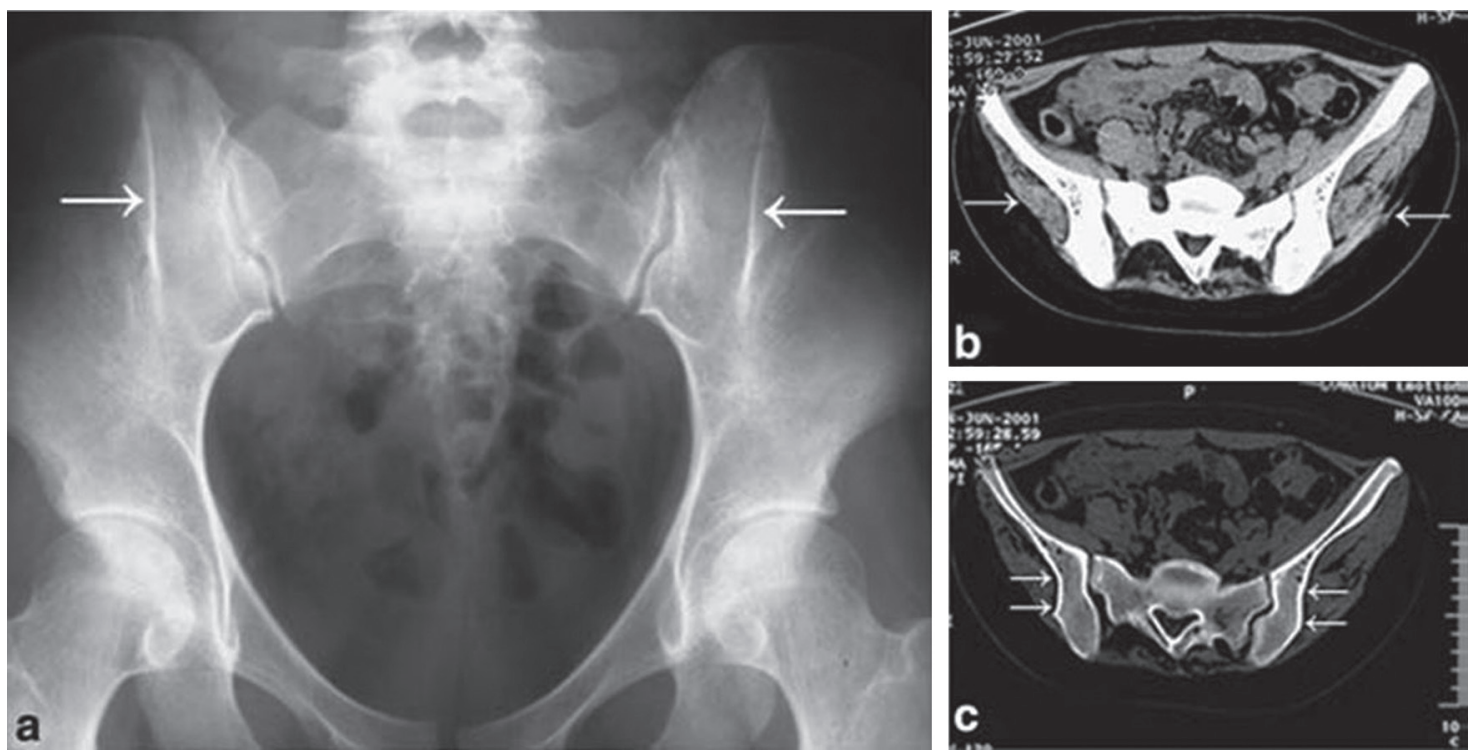

Fig. 4 A 13-year-old boy with fibrosis of the gluteal muscles: a bilateral symmetrical hyperdense line on the ilium is visible on a AP radiograph of the pelvis. The line runs almost parallel to the sacroiliac joint (arrows); b MSCT (soft-tissue mode) shows fibrotic alteration of gluteal muscles with uneven, discontinuous edges and enlarged intermuscular spaces (arrows); c MSCT (bone mode) reveals deformed lateral periosteum of the posterior part of the ilium (arrows) [6]

MSCT study in a soft-tissue mode shows atrophy of the gluteal muscles with uneven discontinuous edges and enlarged intermuscular spaces, calcifications, necrosis of the injection sites and wavy fascia bands. MSCT in the bone mode reveals a deformed lateral periosteum of the posterior part of the ilium which forms the X-ray "sign of the hyperdense line of the ilium" $[6,13,37,67,68]$. Ultrasound of the gluteal regions reveals features such as thinning of the involved gluteal muscles and hyperechoic bands within muscle bundles, indicating fibrosis, as according to Vamshi Krishna Kotha et al. [13, 22, 33, 54, 61].

\section{Classification of RACHJ}

In China, due to frequent cases of RACHJ, several classifications of pathology in children have been developed [11, 16, 44]. However, recent studies show that the authors apply the proposed classifications also to adult patients, especially the classifications proposed by Zhao et al. and Bin et al. [14, 23, 26, 38]. In addition to these classifications, employees of the NIITO MH of the Republic of Uzbekistan developed their own classification of contracture by levels of severity in 2009, based on the results of clinical studies conducted in children [44].

Classification of RACHJ according to severity levels (Zhao et al., 2009) [11]:

\section{Level 1 (mild)}

The extorsion of lower limb is mild, the abduction contracture is less than $15^{\circ}$ with both hip and knee joint in $90^{\circ}$ of flexion or adduction range is less than $20^{\circ}$ with no flexion. Ober's sign and frog squatting sign is weakly positive. The limp gait is not apparent with lateral inclination of pelvis on anteroposterior radiograph being less than $10^{\circ}$.

\section{Level II (moderate)}

The extorsion of lower limb is moderate, the abduction contracture ranges from $15^{\circ}$ to $60^{\circ}$ with both hip and knee joint in $90^{\circ}$ of flexion or adduction range is less than $10^{\circ}$ with no flexion. Ober's sign and frog squatting sign is positive. The limp gait is apparent with lateral inclination of pelvis on anteroposterior radiograph being less than $20^{\circ}$.

\section{Level III (severe)}

The extorsion of lower limb is severe, the abduction contracture is more than $60^{\circ}$ with both hip and knee joint in $90^{\circ}$ of flexion or adduction range is less than $0^{\circ}$ with no flexion. Ober's sign and frog squatting sign is strongly positive. The limp gait is remarkably apparent with lateral inclination of pelvis on anteroposterior radiograph being more than $20^{\circ}$.

Classification of RACHJ according to types (Zhao et al., 2009) [11]:

Type MA Gluteus maximus fibrosis contraction type.

Type MEI Gluteus medius and minimus contraction type.

Type AGM Gluteus maximus, medius and minimus contraction type (all gluteal muscles contraction type)

This classification is easy to use and determine parameters, such as the range of hip joint motion and muscle damage at various levels, but it does not describe the changes in the quadratus femoris muscle described by O.V. Kozhevnikov and S.E. Kralina, which may have an effect on the scope of surgical treatment and, possibly, on the postoperative result of assessing the range of hip motion.

Subsequently, the RACHJ classification proposed by Bin et al. was used by the authors for the diagnosis and treatment of pathology in adult patients [23]. In their opinion, it most accurately describes the clinical manifestations of the disease and anatomical changes.

Patients with gluteal muscle contraction were assigned to 4 categories: 
Type A. Contracture occurred mainly in the iliotibial tract. The patient can squat with knees brought together during the entire squatting process (Fig. 5, a-c). A snapping sound was audible, and the movement of the fibrous band (part of the iliotibial tract) over the greater trochanter was palpable during squatting.

Type A1. In a sitting position, one could cross the legs (Fig. 5, d).

Type A2. In a sitting position, one could partially cross the legs (Fig. 5, e).

Type B. Contracture occurred in the Iliotibial tract and superficial and deep fasciae of the gluteus maximus. A snapping sound was audible, and the movement of the fibrous band (part of the iliotibial tract) over the greater trochanter was palpable during squatting. Moreover, the patient could not bring both knees together while squatting (Fig. 5, f). The involved femur abducted and rotated externally when bent closer to $90^{\circ}$ (Fig. 5, f). The knees were brought together after the fibrous band passed over the greater trochanter, and only then the affected hip was fully bent (Fig. 5, c). In a sitting position, it was impossible to cross the legs (Fig. 5, g).

Type C. Contraction is caused not only by changes in the aforementioned superficial structures, but also by changes involving the gluteus medius, gluteus maximus, piriformis, and the hip joint capsule. By walking, the knees rotate outwards, and they cannot be brought together throughout the entire squatting process (Fig. 5, $\mathrm{f}-\mathrm{h}$ ). In a sitting position, it is impossible to cross the legs, like in type B (Fig. 5, g).

Type C1. Movement of the contraction band was palpable and a snapping sound was audible during squatting;

Type C2. Movement of the contraction band was not palpable or almost absent and a snapping sound was audible during squatting indicating significant adhesions between fibrous tissues. These adhesions often resulted from previous unsuccessful or only partially successful open release procedures.

The classification of the extension abduction contracture of the hip joint in children, proposed in the NIITO MH of the Republic of Uzbekistan [44]:
I. Mild grade. Changes in the skin of the gluteal region and surrounding soft tissues are absent. There are no gait disorders. By passive flexion of the lower limbs in the $0^{\circ}$ position of rotation, a limitation of flexion is from $60^{\circ}$ to $80^{\circ}$. By passive flexion in the hip joint, a snapping sound is audible, after which further flexion of the hip joint becomes freer.

II. Moderate grade. In the gluteal region, there are signs of slight atrophy of the gluteal muscles. Some patients of this grade show a slight forward inclination of the pelvis by walking. In a standing position, the balance is not disturbed, but the movements of the affected limb end with a longer descending of the foot by straight walking forward when a healthy limb is raised due to limited flexion from the affected side. In passive flexion of the lower limbs in the $0^{\circ}$ position of rotation, a limitation of flexion is from $30^{\circ}$ to $60^{\circ}$. Trendelenburg's symptom is negative. Moreover, a child can hardly move independently from a supine position into a sitting position, and in this position, lordosis and tension of the surrounding muscles of the spine increases along with $\mathrm{m}$. tensor fasciae latae.

III. Severe grade. In the gluteal region, atrophy of a significant part of the gluteal muscles is revealed. By palpation of skin impressions in the position of flexion of the hip joint, a dense band is palpated under the skin which often extends from the middle third of the gluteal region to the postero-lateral part of the upper third of the thigh. In the majority of patients, external rotation of the lower extremities is seen by walking. By passive flexion of the lower limbs in the $0^{\circ}$ position of rotation, the limitation of flexion is from $0^{\circ}$ to $30^{\circ}$. Moreover, a child is not able to independently move from a supine position to a sitting position, or significant lordosis is revealed during this transitional change. Patients are not able to touch the floor with their fingertips while standing.

This classification contains descriptions of secondary skin changes and the results of palpation of the gluteal regions; some daily activities are taken into account (transition from a supine position to a sitting position, forward bending of the trunk). This classification is the closest to the syndrome identified in the adult patients we examined.

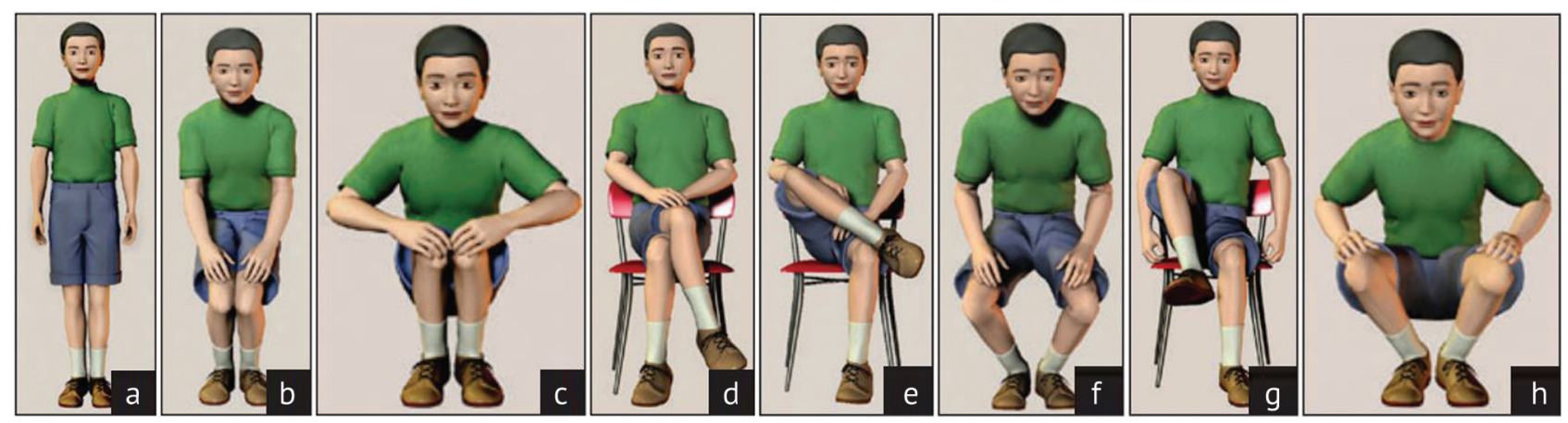

Fig. 5 Classification of RACHJ. Standing position (a). Type A. A clicking sound is heard and the movement of the fibrous cord (part of the iliotibial tract) through the greater trochanter of the femur is heard by squatting (b). Squatting position (c). Type A1. Sitting position, the legs may be completely crossed (d). Type A2. Sitting position, the legs do not cross completely (e). Type B. The affected femur is abducted and rotated externally when bended closer to $90^{\circ}$ (f), and in a sitting position the legs cannot cross (g). Type C. Squatted knees do not come together (h) [23] 


\section{Options of surgical treatment}

The worldwide trend in the treatment of RACHJ is the use of surgical techniques. The conservative method of treatment with rehabilitation programs has an insufficient effect even in level I lesions according to the classification of Zhao et al. (2009) [11, 13]. Surgical treatments in RACHJ range from open surgery to endoscopic technology. Most modern publications have been presented by surgeons from the PRC $[8,11$, 14, 15, 19-21, 23-26, 45, 48, 49, 52], India [38, 54, 55], Africa [35, 36], North America [33] and Russia [22]. The historical information about surgical treatment is publications of authors from European countries [1, 2, 5, 30, 39, 42, 57, 59]. Most authors performed surgical incisions of various lengths and shapes from 6 to $15 \mathrm{~cm}$ longitudinally above or posterior to the greater trochanter. As a rule, the release of fibrously altered muscle areas and Z-shaped lengthening of the gluteus maximus muscle were performed $[2,4,7,11$, $14,16,26,38,39,48,49,53]$. Scully et al. described the surgical method with a posterior approach up to the sciatic tuberosity to release the gluteal muscles and remove fibrously altered tissues [33].

Ekure J. presents a clinical series in which all 28 patients, children up to 12 years old with an average age of 6.4 years, were operated from the posterior approach to the hip joint. The depth of the approach extended until the gluteus maximus muscle was fully released with sequential excision of the fibrosis. A transverse fasciotomy of the iliotibial tract was mandatory. Full and free flexion and adduction of the femur was achieved after careful excision of the fibrosis of the gluteus muscle. The skin was sutured with interrupted sutures with the installation of drainage (Fig. 6) [35].

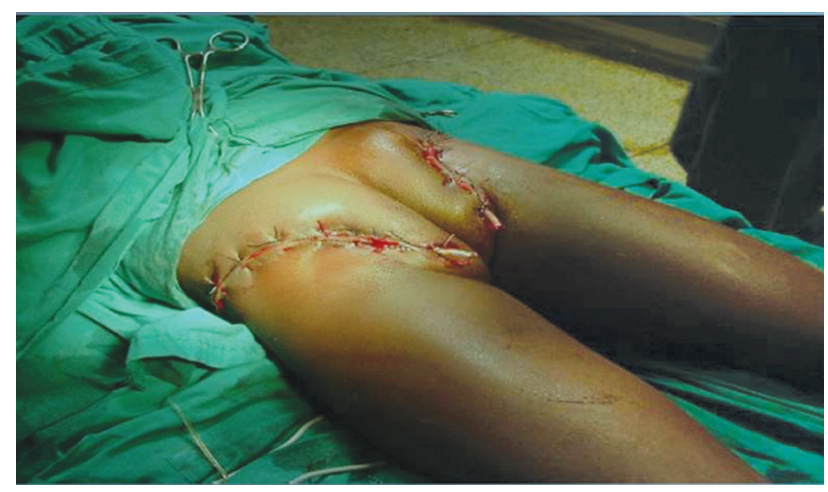

Fig. 6 Posterior approach proposed by the authors and used for surgical treatment in RACHJ [35] with the wound closed with separate interrupted sutures and drainage

The authors point out three complications: two cases of postoperative wound sepsis and one postoperative paresis of the peroneal nerve, which indirectly reflect the traumatism of the surgery and the amount of removed fibrosis [35].

By conducting a targeted search, we were able to find 14 publications related to the treatment of RACHJ in adult patients. Publications with large samples of patients were presented only by authors from China $[8,16,17,19-21,23-26,45,62]$ and two clinical cases were from India [38] and Russia [22].

Thus, Saroj Rai et al. report the results of treatment of 71 patients with RACHJ (33 men and 38 women), mean age 25 years (range, 17 to 42 years). The authors used a longitudinal skin incision of various lengths (range, 5-10 cm), passing over the buttock and the greater trochanter of the femur (Fig. 7). Fibrous bands were separated in sequential order from superficial to deep structures (iliotibial tract, gluteus maximus, gluteus medius, gluteus minimus, piriformis, up to the hip capsule) until full flexion was achieved, adduction and internal rotation of the femur in the hip joint.

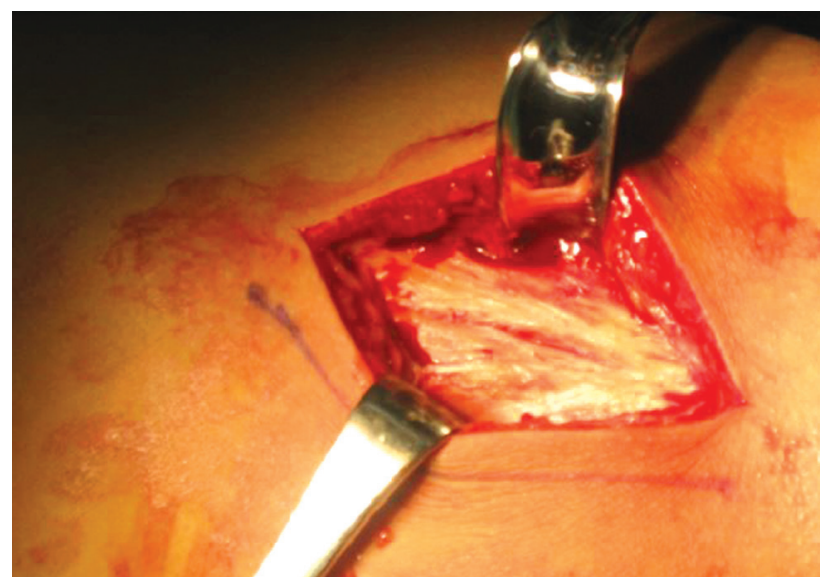

Fig. 7 Longitudinal skin incision over the buttock and greater trochanter of the femur, used by Saroj Rai et al. [15]

Upon 18 months of follow-up, the authors observed excellent functional results in 65, good in four and fair in two patients. In the early postoperative period, there were nine hematomas in the area of the surgical wound, one case of neuropathy of the sciatic nerve and four adhesions around the buttocks, which was caused by a genetic predisposition on the part of the connective tissue. In the late postoperative period, there were five cases of hypertrophic scars [15].

Many authors report a high efficiency of traditional surgical treatment with a correlation of 74.4 to $98.5 \%$ [2, 7, 11, 14-18, 21, 26, 29, 35, 36, 48, 49]. The authors describing clinical series with a minimal sample of patients assessed the treatment results as satisfactory. The authors consider complications to be the negative side of the traditional surgical method reporting different rates, from 0 to $13.9 \%$, such as hypertrophic scars, hematomas, dehiscence of the wound edges, wound infections, damage to the sciatic nerve and cutaneous branches of the femoral nerve, recurrence of the pathology $[8,11-14,17,18$, $26,35,52]$. Ye et al. reported successful results of surgical treatment of 1059 patients at an average age of 23 years (8-43 years) with this pathology using a minimally invasive approach (2012). Patients were followed up for an average of 2.5 years. The authors assessed the functional outcome of the treatment, 
which included such parameters as gait, range of motion in the hip joint, and bringing the knees together during squatting. The authors also reported only three cases of acute damage to the branches of the femoral artery in the femoral neck, which was repaired through a small approach [23].

However, despite the minimal invasiveness and good results of the surgical method, the authors do not properly describe the technical difficulties and limitations of the technique during the operation, which is performed blindly from small incisions. This approach may end in incomplete release of fibrous bands and damage to the neurovascular bundles in the area of the incisions performed.

Due to the complications of the traditional surgical method that have a negative impact on the functional and cosmetic parameters of patients, the development of endoscopic technologies of interventions tends to choosing them for RACHJ surgical treatment to minimize the risks of complications and cosmetic defects in the wound area. The authors of the methods report excellent results in the treatment of this pathology in terms of range of motion in the hip joints, minimal cosmetic wounds, less severity of postoperative pain, early rehabilitation and a short stay in the hospital $[8,12-15,19,20,24,25,38,45]$.
The comparison of the traditional surgical method with the endoscopic method did not find significant differences in the duration of the operation, number of intra-operative complications, in clinical outcomes and in the recurrence rate. It was also reported that an unsatisfactory result was revealed in 4 patients with level III lesion and AGM type according to the classification of Zhao et al. The patients were re-operated with the traditional surgical technique, which indicates certain limitations of the endoscopic method in the treatment of severe forms of the pathology [14].

The surgical method remains the main method of treatment, the choice of which directly depends on the severity of the pathology. Thus, patients with gluteal muscle fibrosis belonging to level III and AGM type according to the classification of "gluteal muscle contractions" (Zhao et al. (2009) [11], to type $\mathrm{C} 2$ according to the classification proposed by Bin et al. (2012) [23] and severe grade according to the classification of the Scientific Research Institute of Traumatology and Orthopedics of the Ministry of Health of the Republic of Uzbekistan (2009) [44], are operated only from an open surgical approach. Open and the endoscopic method may be used for all other forms of the pathology.

\section{CONCLUSION}

Having studied the available literature, we believe that there are big shortcomings in the coverage of this problem in our country. There are no standards for diagnosis, treatment and rehabilitation of adult patients over the age of 18 with RACHJ. We also opine that not only the gluteal muscles, but also deep-lying muscles such as $\mathrm{m}$. pectineus, m. piriformis, m. quadratus femoris, $\mathrm{m}$. obturatorius internus, may be involved in the pathological process. They are mainly responsible for the external rotation of the hip and, when degenerated into fibrous tissue, play a large role in the pathological external rotation of the femur and abduction in their flexion in the hip joint due to limited or impossible stretching.

Lesions of these muscles may, possibly, be detected by clinical examination, but so far only fibrosis of the m. quadratus is convincingly visualized in MRI images [22]. Fibrous changes in the remaining muscles are detected only during surgery and are not described in any of the currently proposed classifications. In this regard, at the first stage, it would be advisable, using the classifications of contractures and treatment methods developed by our Chinese colleagues, to conduct studies with radiologists to describe this pathology and develop a standard for treating patients with RACHJ. The standard of treatment will be in demand in the regions of the Russian Federation that are endemic for this pathology, such as the Republic of Tyva, as well as in the Chukotka, Yamalo-Nenets, Khanty-Mansiysk Autonomous Districts of the Russian Federation, where the number of such patients may turn out to be quite large by targeted examination.

\section{REFERENCES}

1. Valderrama J.A.F. A cause of limited flexion and adduction of the hip in children. J. Bone Joint Surg. Br., 1970, vol. 52, pp. 179.

2. Valderrama J.A.F., Esteve de Miguel R. Fibrosis of the gluteus maximus: a cause of limited flexion and adduction of the hip in children. Clin. Orthop. Relat. Res., 1981, no. 156, pp. 67-78.

3. Hang Y.S. Contracture of the hip secondary to fibrosis of the gluteus maximus muscle. J. Bone Joint Surg. Am., 1979 , vol. 61, no. 1, pp. 52-55.

4. Gao G.X. Idiopathic contracture of the gluteus maximus muscle in children. Arch. Orthop. Trauma Surg., 1988, vol. 107, no. 5, pp. 277-279. DOI: $10.1007 /$ BF00451506.

5. Brignall C.G., Brown R.M., Stainsby G.D. Fibrosis of the gluteus maximus as a cause of snapping hip. A case report. J. Bone Joint Surg. Am., 1993, vol. 75, no. 6, pp. 909-910. DOI: 10.2106/00004623-199306000-00012.

6. Cai J.H., Gan L.F., Zheng H.L., Li H. Iliac hyperdense line: a new radiographic sign of gluteal muscle contracture. Pediatr. Radiol., 2005, vol. 35, no. 10, pp. 995-997. DOI: 10.1007/s00247-005-1519-2.

7. Liu G.H., Cao F.Q., Yang S.H., Zhu J.F. Factors influencing the treatment of severe gluteal muscle contracture in children. J. Pediatr. Orthop. B, 2011, vol. 20, no. 2, pp. 67-69. DOI: 10.1097/BPB.0b013e328341bcb2.

8. Zhang X., Jiang X., He F., Liang Z., You T., Jin D., Zhang W. Arthroscopic revision release of gluteal muscle contracture after failed primary open surgery. Int. Orthop., 2017, vol. 41, no. 8, pp. 1521-1526. DOI: 10.1007/s00264-016-3354-5. 
9. Dongak A.V. Puti optimizatsii sistemy lecheniia detei s regionalnoi ortopedicheskoi patologiei na territoriiakh s nizkoi plotnostiu naseleniia (na primere respubliki Tyva). Avtoref. doss. ...cand. med. nauk [Ways to optimize the treatment system for children with regional orthopedic pathology in areas with a low population density (on the example of the Republic of Tyva. Cand. med. sci. diss. abstr.]. Novosibirsk, 2008,30 p. (in Russian)

10. Aggarwal A., Singh S., Singh M., Chauhan R. Idiopathic bilateral gluteus maximus contracture: a case report and review of literature. Acta Orthop. Belg., 2005, vol. 71, no. 4, pp. 493-495.

11. Zhao C.G., He X.J., Lu B., Li H.P., Wang D., Zhu Z.Z. Classification of gluteal muscle contracture in children and outcome of different treatments. BMC Musculoskelet. Disord., 2009, vol. 10, pp. 34. DOI: 10.1186/1471-2474-10-34.

12. Alves K., Katz J.N., Sabatini C.S. Gluteal fibrosis and its surgical treatment. J. Bone Joint Surg. Am., 2019, vol. 101, no. 4, pp. 361-368. DOI: 10.2106/ JBJS.17.01670.

13. Rai S., Meng C., Wang X., Chaudhary N., Jin S., Yang S., Wang H. Gluteal muscle contracture: diagnosis and management options. SICOT J., 2017, vol. 3, pp. 1. DOI: 10.1051/sicotj/2016036.

14. Fu D., Yang S., Xiao B., Wang H., Meng C. Comparison of endoscopic surgery and open surgery for gluteal muscle contracture. J. Pediatr. Orthop., 2011, vol. 31, no. 5, pp. e38-e43. DOI: 10.1097/BPO.0b013e31821f509c.

15. Rai S., Jin S., Meng C., Chaudhary N., Tamang N., Wang X., Liu X., Wang H., Yang S. Arthroscopic release using F and C method versus conventional open release method in the treatment of gluteal muscle contracture: a comparative study. BMC Musculoskelet. Disord., 2017, vol. 18, no. 1, pp. 113. DOI: 10.1186/s12891-017-1484-6.

16. Liu G., Du J., Yang S., Zheng Q., Li J. A retrospective analysis of the gluteal muscles contracture and discussion of the relative problems. J. Tongji Med. Univ., 2000, vol. 20, no. 1, pp. 70-71. DOI: 10.1007/BF02887682.

17. He X., Li H., Wang D. [Classification and management of the gluteal muscles contracture]. Chin. J. Orthop., 2003, vol. 23, pp. 96-100. (in Chinese)

18. Gonzalez R. Gluteal retractions: classification and treatment techniques. Aesthet. Surg. J., 2006, vol. 26, no. 5, pp. 537-550. DOI: 10.1016/j. asj.2006.08.007.

19. Liu Y.J., Xue J., Zhou M., Wang Z.G., Li Z.L., Cai X., Wei M., Wang Y., Zhu J.L. [Arthroscope monitored solution of adult intramuscular injection associated gluteal muscle contracture by radiofrequency]. Zhonghua Wai Ke Za Zhi, 2008, vol. 46, no. 13, pp. 970-972. (in Chinese)

20. Liu Y.J., Wang Y., Xue J., Lui P.P., Chan K.M. Arthroscopic gluteal muscle contracture release with radiofrequency energy. Clin. Orthop. Relat. Res., 2009, vol. 467, no. 3, pp. 799-804. DOI: 10.1007/s11999-008-0595-7.

21. Chen X., Tang X., Jiang X., Wang D., Peng M., Liu L. [Diagnosis and treatment of unilateral gluteal muscle contracture]. Zhongguo Xiu Fu Chong Jian Wai Ke Za Zhi, 2011, vol. 25, no. 5, pp. 530-532. (in Chinese)

22. Kozhevnikov O.V., Kralina S.E. Idiopaticheskaia razgibatelno-otvodiashchaia kontraktura tazobedrennogo sustava [Idiopathic extension-abduction contracture of hip joint]. Vestnik Travmatologii i Ortopedii im.N.N. Priorova, 2012, vol. 19, no. 1, pp. 74-76. (in Russian)

23. Ye B., Zhou P., Xia Y., Chen Y., Yu J., Xu S. New minimally invasive option for the treatment of gluteal muscle contracture. Orthopedics, 2012, vol. 35, no. 12, pp. e1692-e1698. DOI: 10.3928/01477447-20121120-11.

24. Liu Y.J., Wang Z.G., Wang J.L., Li S.Y., Li H.F., Qu F., Xue J., Qi W., Liu C., Zhu J.L. [Clinical classification of gluteal muscle contracture under arthroscopy]. Zhongguo Gu Shang, 2013, vol. 26, no. 6, pp. 468-470. (in Chinese)

25. Zhao G., Liu Y.J., Wang J.L., Qi W., Qu F., Yuan B.T., Wang J.T., Shen X.Z., Liu Y., Zhu J.L. [Etiological analysis and significance of anterior knee pain induced by gluteal muscles contracture]. Zhongguo Gu Shang, 2014, vol. 27, no. 12, pp. 1000-1002. (in Chinese)

26. Xu J., Geng X., Muhammad H., Wang X., Huang J.Z., Zhang C., Ma X. Comparison of the incisions for the open surgical treatment of gluteal muscle contracture. J. Pediatr. Orthop. B, 2014, vol. 23, no. 5, pp. 435-440. DOI: 10.1097/BPB.0000000000000067.

27. Shen Y.S. Abduction contracture of the hip in children. J. Bone Joint Surg. Br., 1975, vol. 57, no. 4, pp. 463-465.

28. Shanmugasundaram T.K. Post-injection fibrosis of skeletal muscle: a clinical problem. A personal series of 169 cases. Int. Orthop., 1980, vol. 4, no. 1, pp. 31-37. DOI: 10.1007/BF00266601.

29. Chung D.C., Ko Y.C., Pai H.H. [A study on the prevalence and risk factors of muscular fibrotic contracture in Jia-Dong Township, Pingtung County, Taiwan]. Gaoxiong Yi Xue Ke Xue Za Zhi, 1989, vol. 5, no. 2, pp. 91-95. (in Chinese)

30. Sirinelli D., Oudjhane K., Khouri N. Case report 605: Gluteal amyotrophy: a late sequela of intramuscular injection. Skeletal Radiol., 1990, vol. 19, no. 3, pp. 221-223. DOI: 10.1007/BF00204104.

31. Ko Y.C., Chung D.C., Pai H.H. Intramuscular-injection-associated gluteal fibrotic contracture and hepatitis B virus infection among school children. Gaoxiong Yi Xue Ke Xue Za Zhi, 1991, vol. 7, no. 7, pp. 358-362.

32. Huang Y., Li J., Lei W. [Gluteal muscle contracture: etiology, classification and treatment]. Chin. J. Orthop., 1999, vol. 19, pp. 106-108. (in Chinese)

33. Scully W.F., White K.K., Song K.M., Mosca V.S. Injection-induced gluteus muscle contractures: diagnosis with the "reverse Ober test" and surgical management. J. Pediatr. Orthop., 2015, vol. 35, no. 2, pp. 192-198. DOI: 10.1097/BPO.0000000000000238.

34. Sun X. [An investigation on injectional gluteal muscle contracture in childhood in Mianyang City]. Zhonghua Liu Xing Bing Xue Za Zhi, 1990, vol. 11 , no. 5 , pp. 291-294. (in Chinese)

35. Ekure J. Gluteal fibrosis. A report of 28 cases from Kumi Hospital, Uganda. East Cent. Afr. J. Surg., 2007, vol. 12, no. 1.

36. Nikolaou S., Asige E., Francis O., Abaikol R. Gluteal fibrosis; a case series in eastern Uganda. Could our malarial treatment be causing long-term disability? Int. J. Surg., 2014, vol. 12, no. 3, pp. S64.

37. Chiang C.L., Tsai M.Y., Chang W.N., Chen C.K. Aberrant femoral torsion presenting with frog-leg squatting mimicking gluteal muscle contracture. Clin. Orthop. Relat. Res., 2012, vol. 470, no. 4, pp. 1165-1170. DOI: 10.1007/s11999-011-2084-7.

38. Pathak A., Shukla J. Idiopathic Bilateral Gluteus Maximus Contracture in Adolescent Female: A Case Report. J. Orthop. Case Rep., 2013, vol. 3, no. 1, pp. 19-22.

39. Yadav S.S. Extension contracture of the hip due to idiopathic fibrosis of the gluteus maximus. Int. Surg., 1978, vol. 63, no. 1, pp. 27-28.

40. Edgar E.M., Carlson H.L., Egan R.A., Riccelli L.P., Cupler E.J. Congenital absence of gluteal muscles, optic nerve hypoplasia, and central nervous system hamartomas. Clin. Dysmorphol., 2012, vol. 21, no. 2, pp. 106-108. DOI: 10.1097/MCD.0b013e32834e7fb9.

41. Mehta M.H. Bilateral congenital contracture of the ilio-tibial tract. J. Bone Joint Surg. Br., 1972, vol. 54, no. 3, pp. 532-534.

42. Wolbrink A.J., Hsu Z., Bianco A.J. Abduction contracture of the shoulders and hips secondary to fibrous bands. J. Bone Joint Surg. Am., 1973, vol. 55 , no. 4 , pp. $844-846$.

43. Ma C.X., Fang L.G., Liu G.L. [Injection caused gluteal muscle contracture]. Chin. J. Orthop., 1978, vol. 16, pp. 345-346. (in Chinese)

44. Dzhuraev A.M., Kadyrov I.M. Klinicheskie aspekty diagnostiki i lecheniia razgibatelno-otvodiashchei kontraktury tazobedrennogo sustava $\mathrm{u}$ detei [Clinical aspects of diagnosis and treatment of the hip extensive-abduction contracture in children]. Vestnik Ortopedii, Travmatologii $i$ Protezirovaniia, 2009, no. 1. (in Russian)

45. Huang J.B., Ge H., Zhang Y.L., Liu C.T., Xue C., Chen Y.C., Wu P., Cheng B. The role of arthroscopic release of gluteal muscle contracture in improving patellofemoral instability. J. Orthop. Surg. Res., 2019, vol. 14, no. 1, pp. 159. DOI: 10.1186/s13018-019-1187-9.

46. Shen Y.S. Gluteus maximus contracture. Clin. Orthop. Relat. Res., 1982, no. 162, pp. 185-188.

47. Ni B., Li M. [The effect of children's gluteal muscle contracture on skeleton development]. Sichuan Da Xue Xue Bao Yi Xue Ban, 2007, vol. 38, no. 4, pp. 657-659, 677. (in Chinese)

48. Liu G., Yang S., Du J., Zheng Q., Shao Z., Yang C. Treatment of severe gluteal muscle contracture in children. J. Huazhong Univ. Sci. Technolog. Med. Sci., 2008, vol. 28, no. 2, pp. 171-173. DOI: 10.1007/s11596-008-0214-6.

49. Zha K., Liu G., Yang S., Cao F. Z-plasty for severe gluteal muscle contracture in children. J. Orthop. Surg. (Hong Kong), 2016, vol. 24, no. 3, pp. 383-386. DOI: 10.1177/1602400323.

50. Ganel A., Blankstein A. Congenital gluteus maximus contracture. Orthop. Rev., 1989, vol. 18, no. 1, pp. 95-97.

51. Chen S.S., Chien C.H., Yu H.S. Syndrome of deltoid and/or gluteal fibrotic contracture: an injection myopathy. Acta Neurol. Scand., 1988, vol. 78, 
no. 3, pp. 167-176. DOI: 10.1111/j.1600-0404.1988.tb03640.x.

52. Zhang K., Li P., Zhong-Ke L., Ren H., Tang X., Chun-Hui M., Tang M. [Treatment of gluteus contracture with small incision: a report of 2518 cases]. Chin. J. Orthop. Trauma, 2007, vol. 20, pp. 851-852. (in Chinese)

53. Chen H.S., Yang X.L. [Insertion of gluteus maximus tendo-chilles lengthening with Z-shaped for the treatment of severe gluteal muscle contracture]. Zhongguo Gu Shang, 2015, vol. 28, no. 6, pp. 524-526. (in Chinese)

54. Kotha V.K., Reddy R., Reddy M.V., Moorthy R.S., Kishan T.V. Congenital gluteus maximus contracture syndrome - a case report with review of imaging findings. J. Radiol. Case Rep., 2014, vol. 8, no. 4, pp. 32-37. DOI: 10.3941/jrcr.v8i4.1646.

55. Sinha S., Gupta S., Kanojia R.K. Bilateral Gluteus Maximus Contracture in a Young Child: A Case Report and Review of Literature. J. Orthop. Case Rep., 2019, vol. 9, no. 2, pp. 60-63. DOI: 10.13107/jocr.2250-0685.1372.

56. Al Bayati M.A., Kraidy B.K. Gluteal muscle fibrosis with abduction contracture of the hip. Int. Orthop., 2016 , vol. 40, no. 3, pp. 447-451. DOI: 10.1007/s00264-015-2836-1.

57. Carnevale A., del Castillo V., Sotillo A.G., Larrondo J. Congenital absence of gluteal muscles. Report of two sibs. Clin. Genet., 1976, vol. 10, no. 3, pp. 135-138. DOI: 10.1111/j.1399-0004.1976.tb00025.x.

58. Lixihua L., Zhangqing Z., Shengpingquan S., Zhaolei Z., Zhaoli Z., Cuixuee C., Liuxiaoqin L. The clinical and pathological analysis of the uniform type I fiber myopathy with brain atrophy and gluteal muscle contractures. Neuromuscul. Disord., 2010, vol. 20, no. 9-10, pp. 613-613.

59. Fluixa R.P., Pérez R.J.L., Cañizares P.S. Fibrosis glútea: ¿esencial o secundaria? Rev. Esp. Cir. Osteoart., 1995, vol. 30, pp. $202-206$.

60. Parano E., Falsaperla R., Pavone V., Toscano A., Bolan E.A., Trifiletti R.R. Intrafamilial phenotypic heterogeneity of the Poland complex: a case report. Neuropediatrics, 1995, vol. 26, no. 4, pp. 217-219. DOI: 10.1055/s-2007-979758.

61. Li Q., Lingyan Z., Yan L., Yulan P. The role of ultrasonography in the diagnosis of gluteal muscle contracture. Skeletal Radiol., 2011, vol. 40, no. 2, pp. 215-221. DOI: 10.1007/s00256-009-0869-5.

62. Oleas-Santillán G., Bowen J.R. Anterior Hip Dislocation from Post-injection Gluteal Muscular Fibrosis: Case Report. JBJS Case Connect., 2019, vol. 9, no. 2, pp. e0250. DOI: 10.2106/JBJS.CC.18.00250.

63. Yuan B.T., Qu F., Wang S.X., Qi W., Shen X.Z., Li C.B., Liu Y.J. Histology and molecular pathology of iliotibial tract contracture in patients with gluteal muscle contracture. Biosci. Rep., 2019, vol. 39, no. 9, BSR20181351. DOI: 10.1042/BSR20181351.

64. Zhao C.G., He X.J., Lu B., Li H.P., Kang A.J. Increased expression of collagens, transforming growth factor-beta1, and -beta3 in gluteal muscle contracture. BMC Musculoskelet. Disord., 2010, vol. 11, pp. 15. DOI: 10.1186/1471-2474-11-15.

65. Zhang X., Ma Y., You T., Tian X., Zhang H., Zhu Q., Zhang W. Roles of TGF- $\beta /$ Smad signaling pathway in pathogenesis and development of gluteal muscle contracture. Connect. Tissue Res., 2015, vol. 56, no. 1, pp. 9-17. DOI: 10.3109/03008207.2014.964400.

66. Chen C.K., Yeh L., Chang W.N., Pan H.B., Yang C.F. MRI diagnosis of contracture of the gluteus maximus muscle. AJR Am. J. Roentgenol., 2006, vol. 187, no. 2, pp. W169-W174. DOI: 10.2214/AJR.05.0319.

67. Wang L., Bao J., Jiang J.T., Pan Zh., Hu K., Jiang J., Zhang H., Sun J., Yuan Y. [CT diagnosis of gluteal muscle contracture in children]. Chin. J. Radiol., 2004, vol. 38, no. 4, pp. 365-367. (in Chinese)

68. You T., Yang B., Zhang X.T., Ren S.Y., Bai L., Jiao F.J., Jiang X.C., Guan S.Y., Zhang W.T. A possible prediction of dystocia at the time of cesarean delivery: Gluteal muscle contracture, a single center experience from China. Medicine (Baltimore), 2020, vol. 99, no. 7, pp. e19138. DOI: 10.1097/ MD.0000000000019138.

The article was submitted 26.05.2020; approved after reviewing 16.09.2020; accepted for publication 23.08.2021.

\section{Information about the authors:}

1. Ertine S. Chyndyn-ool - M.D., MynameisTreasure@mail.ru;

2. Vitaliy V. Pavlov - Doctor of Medical Sciences, pavlovdoc@mail.ru;

3. Aleksandr G. Samokhin - Candidate of Medical Sciences, motorist@inbox.ru.

Informed consent The patient gave voluntary informed consent for publication.

Conflicts of interest None.

Funding source The study was not sponsored. 